\title{
A BEM-FEM model for the dynamic analysis of building structures founded on elastic or poroelastic soils *
}

\author{
A. Santana, J. J. Aznárez, L. A. Padrón, O. Maeso \\ Instituto Universitario de Sistemas Inteligentes y Aplicaciones Numéricas en Ingeniería (SIANI) \\ Universidad de Las Palmas de Gran Canaria, 35017 Las Palmas de Gran Canaria, Spain
}

\begin{abstract}
This work presents a time-harmonic boundary element - finite element three-dimensional model for the dynamic analysis of building structures founded on elastic or poroelastic soils. The building foundation and soil domains are modelled as homogeneous, isotropic, elastic or poroelastic media using boundary elements. The foundation can also be modelled as a perfectly rigid body coupled to soil and structure. The buildings are modelled using Timoshenko beam finite elements that include the torsional eccentricity of non-symmetrical buildings. The excitation model includes far-field plane seismic waves of $\mathrm{P}, \mathrm{S}$ or Rayleigh type for viscoelastic soils and $\mathrm{P} 1$ and $\mathrm{S}$ type for poroelastic soils. Modelling foundation and structure as rigid body and Timoshenko beam respectively, conveys important benefits such as a significant reduction in the number of degrees of freedom in the problem, which allows to study problems involving several building structures and the interactions between them with acceptable computational effort. Results are presented for validation purposes first, and for studying the influence of modelling the soil as a viscoelastic or poroelastic region afterwards. A study of the modelling of structure-soil-structure interaction effects is also performed.
\end{abstract}

Keywords: soil-structure interaction, structure-soil-structure interaction, numerical model, boundary element method, poroelastic soil, building structures

\section{Introduction}

The main goal of this work is the formulation of a frequency-domain coupled boundary element finite element (BEM-FEM) model to study the dynamic and seismic response of a building or a group of building structures founded on elastic or poroelastic soils. For this purpose, a previous multidomain BEM model (Maeso et al, 2002, 2004, 2005; Aznárez et al, 2006) was enhanced by adding new features in order to reduce the computational cost when dealing with that kind of problems. That multidomain BEM formulation has been used to study different problems of interest in the field of earthquake engineering, such as, for instance, the seismic response of: arch dams including the effects of spatial distribution of the excitation and of the presence of poroelastic sediments (Maeso et al, 2002, 2004); piles and groups of piles in poroelastic soils (Maeso et al, 2005); or non-slender buried structures and the effects of its flexibility in the response (Vega et al, 2013).

In the model presented herein, the soil is modelled as an elastic or poroelastic region using boundary elements, as briefly presented in section 2. When the hypothesis of infinite rigidity is applicable to the foundation, this model allows the incorporation of regions with rigid body

${ }^{*}$ This is the pre-peer reviewed version of the following article: A BEM-FEM model for the dynamic analysis of building structures founded on viscoelastic or poroelastic soils. Bull Earthq Eng (2015) 14(1):115-138. The final publication is available at Springer via http://dx.doi.org/10.1007/s10518-015-9817-z. 
behavior embedded in the soil. The coupling between the boundary element mesh and the rigid body is possible through a numerical strategy based on the application of additional compatibility and equilibrium equations at the soil-foundation interfaces. Then, the movement of the foundation can be measured with only an arbitrary point of reference, yielding a considerable reduction in the number of degrees of freedom of the problem. The implementation of this strategy to the BEM system of equations is explained in section 3.

The building structures are modelled as elastic homogeneous beams using two-noded finite elements including the shear deformation (Timoshenko's beam theory), and also the torsional eccentricity for non-symetrical superstructures. In section 4, the modified stiffness matrix (taking the effects of the torsional eccentricity into account) and the characteristics of this finite element are presented. The point of reference of the rigid domain will be used to couple the equations of motion of the superstructure to the system of equations that defines the behavior of the soil and the foundation.

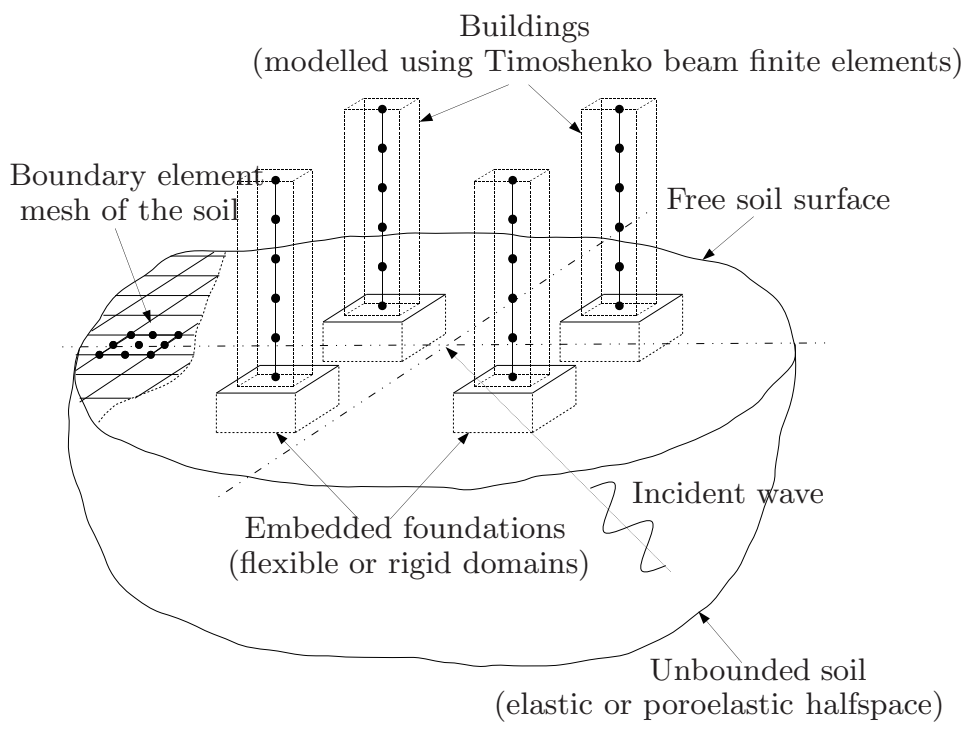

Figure 1: Group of four nearby buildings founded on a halfspace. Sketch of main elements included in the model.

In short, the BEM-FEM model presented in this paper is able to rigorously represent the essential aspects of the problem at hand while being, at the same time, versatile and computationally efficient. The model could be used not only to address problems involving building structures (as sketched in Figure 1, where the main aspects of the model are presented), but also, wind turbines or other type of structures. Previous works, both analytical and numerical, with common features to the present research are, among others, those of Luco and Cortesse (1973); Wong and Trifunac (1975); Simpson (1978); Luco and Wong (1982); Luco (1986); Hejal and Chopra (1989); Todorovska and Trifunac (1990); Wang and Schmid (1992); Todorovska and Al Rjoub (2006a,b)

In section 5, some comparison results for validation purposes are presented together with results to study the influence of the viscoelastic or poroelastic nature of the soil in the response and the effects of the structure-soil-structure interaction. Final conclusions are summarized in section 6 .

\section{Boundary element model for the soil (Soil boundary element equations)}

In this work, the regions discretized using the boundary element method (soil, foundation and superstructure in the multidomain BEM approach, and only soil in the BEM - FEM approach) are modelled as linear homogeneous, isotropic, elastic or poroelastic regions, and welded conditions are assumed between the different domains. The boundaries are discretized into three-dimensional 
quadrilateral (9-noded) and triangular (6-noded) quadratic boundary elements yielding to the traditional boundary element system of equations

$$
\mathbf{H u}=\mathbf{G} \mathbf{p}
$$

for an elastic soil, where the elements of the matrices $\mathbf{H}$ and $\mathbf{G}$ are obtained by integration of the 3-D time-harmonic viscoelastic fundamental solution times the corresponding shape functions, respectively, and where $\mathbf{u}$ and $\mathbf{p}$ are the vectors of the nodal displacements and tractions. Corner problems are solved by means of a non-nodal collocation strategy, which also allows using nonconforming meshes (see e.g.: Aliabadi, 2002; Aznárez, 2002).

In the case of water-saturated soils, Biot's theory (Biot, 1956) for poroelastic media is adopted. Thus, the vectors of the nodal normal fluid displacements $\mathbf{U}$ and the nodal fluid equivalent stresses $\tau$ are also variables of the problem. The boundary element system of equations including these variables may be expressed as follows (Domínguez, 1992; Maeso et al, 2005):

$$
\left[\begin{array}{ll}
\mathbf{H}^{\mathrm{ss}} & \mathbf{H}^{\mathrm{sw}} \\
\mathbf{H}^{\mathrm{ws}} & \mathbf{H}^{\mathrm{ww}}
\end{array}\right]\left[\begin{array}{l}
\mathbf{u} \\
\boldsymbol{\tau}
\end{array}\right]=\left[\begin{array}{ll}
\mathbf{G}^{\mathrm{ss}} & \mathbf{G}^{\mathrm{sw}} \\
\mathbf{G}^{\mathrm{ws}} & \mathbf{G}^{\mathrm{ww}}
\end{array}\right]\left[\begin{array}{c}
\mathbf{p} \\
\mathbf{U}
\end{array}\right]
$$

where the superscripts 's' and 'w' denote respectively the solid skeleton and the pore water of the poroelastic medium. The elements of the submatrices $\mathbf{H}$ and $\mathbf{G}$ are obtained by integration of the 3-D time-harmonic poroelastic fundamental solution times the corresponding shape functions, over the boundary elements. More details of this formulation and its numerical aspects can be found in Domínguez (1993); Maeso et al (2005) and Aznárez et al (2006).

If plane harmonic waves impinging the foundation site from a far source are considered, the presence of the foundation disrupts in the incident wave fields of a uniform elastic or poroelastic halfspace. The incident wave field is completely known. The fields of the total displacements $\mathbf{u}_{\mathrm{T}}$ and tractions $\mathbf{p}_{\mathrm{T}}$ are the superposition of the incident and scattered fields, denoted by subscript I and $\mathrm{S}$ respectively, so that $\mathbf{u}_{\mathrm{T}}=\mathbf{u}_{\mathrm{I}}+\mathbf{u}_{\mathrm{S}}$ and $\mathbf{p}_{\mathrm{T}}=\mathbf{p}_{\mathrm{I}}+\mathbf{p}_{\mathrm{S}}$.

The algebraic BEM system of equations (1) considering the soil as an elastic halfspace may be written for the scattered fields as:

$$
\mathbf{H}\left(\mathbf{u}_{\mathrm{T}}-\mathbf{u}_{\mathrm{I}}\right)=\mathbf{G}\left(\mathbf{p}_{\mathrm{T}}-\mathbf{p}_{\mathrm{I}}\right)
$$

For a poroelastic halfspace, the incident fields of the fluid equivalent stress and the normal fluid displacement are respectively denoted by $\boldsymbol{\tau}_{\mathrm{I}}$ and $\mathbf{U}_{\mathrm{I}}$. Then, being $\boldsymbol{\tau}_{\mathrm{T}}=\boldsymbol{\tau}_{\mathrm{I}}+\boldsymbol{\tau}_{\mathrm{S}}$ and $\mathbf{U}_{\mathrm{T}}=\mathbf{U}_{\mathrm{I}}+\mathbf{U}_{\mathrm{S}}$, the system of equations (2) for the scattered fields may be written as:

$$
\left[\begin{array}{ll}
\mathbf{H}^{\mathrm{ss}} & \mathbf{H}^{\mathrm{sw}} \\
\mathbf{H}^{\mathrm{ws}} & \mathbf{H}^{\mathrm{ww}}
\end{array}\right]\left[\begin{array}{c}
\mathbf{u}_{\mathrm{T}}-\mathbf{u}_{\mathrm{I}} \\
\boldsymbol{\tau}_{\mathrm{T}}-\boldsymbol{\tau}_{\mathrm{I}}
\end{array}\right]=\left[\begin{array}{cc}
\mathbf{G}^{\mathrm{ss}} & \mathbf{G}^{\mathrm{sw}} \\
\mathbf{G}^{\mathrm{ws}} & \mathbf{G}^{\mathrm{ww}}
\end{array}\right]\left[\begin{array}{c}
\mathbf{p}_{\mathrm{T}}-\mathbf{p}_{\mathrm{I}} \\
\mathbf{U}_{\mathrm{T}}-\mathbf{U}_{\mathrm{I}}
\end{array}\right]
$$

The results presented in section 5 for viscoelastic soils have been computed considering harmonic planar incident waves of $\mathrm{P}$ and $\mathrm{S}$ types with vertical incidence or Rayleigh wave type. In the case of poroelastic soils, vertical incident wave fields are considered of P1 and S type. Incident P2 waves in saturated soils with realistic properties are highly damped and are therefore not observed in practice, reason why they have not been considered in this study.

\section{Rigid body model for the foundation}

When the hypothesis of perfect rigidity does apply, assuming the foundation as a rigid body implies a significant reduction of the degrees of freedom of the problem.

The strategy implemented in this work to include rigid body restrictions is one of the three techniques proposed by Thomazo and Mesquita (2007) and applied in two-dimensional problem by these authors. The process may be summarized as the task of incorporating kinematic compatibility restrictions and equilibrium conditions into the matrices of equations (3) and (4). Let us assume that the rigid behavior does apply to the foundation, which is embedded in an elastic or poroelastic 
halfspace (see figure 2). Let $\Gamma_{s}$ and $\Gamma_{r}$ be the free soil surface and the rigid interface between soil and foundation, respectively. Then, equations (3) and (4) can be written as:

$$
\left[\begin{array}{ll}
\mathbf{H}_{s s} & \mathbf{H}_{s r} \\
\mathbf{H}_{r s} & \mathbf{H}_{r r}
\end{array}\right]\left[\begin{array}{l}
\mathbf{u}_{s}-\left(\mathbf{u}_{\mathrm{I}}\right)_{s} \\
\mathbf{u}_{r}-\left(\mathbf{u}_{\mathrm{I}}\right)_{r}
\end{array}\right]=\left[\begin{array}{ll}
\mathbf{G}_{s s} & \mathbf{G}_{s r} \\
\mathbf{G}_{r s} & \mathbf{G}_{r r}
\end{array}\right]\left[\begin{array}{l}
\mathbf{p}_{s}-\left(\mathbf{p}_{\mathrm{I}}\right)_{s} \\
\mathbf{p}_{r}-\left(\mathbf{p}_{\mathrm{I}}\right)_{r}
\end{array}\right]
$$

and

$\left[\begin{array}{llll}\mathbf{H}_{s s}^{\mathrm{ss}} & \mathbf{H}_{s r}^{\mathrm{ss}} & \mathbf{H}_{s s}^{\mathrm{sw}} & \mathbf{H}_{s r}^{\mathrm{sw}} \\ \mathbf{H}_{r s}^{\mathrm{ss}} & \mathbf{H}_{r r}^{\mathrm{ss}} & \mathbf{H}_{r s}^{\mathrm{sw}} & \mathbf{H}_{r r}^{\mathrm{sw}} \\ \mathbf{H}_{s s}^{\mathrm{ws}} & \mathbf{H}_{s r}^{\mathrm{ws}} & \mathbf{H}_{s s}^{\mathrm{ww}} & \mathbf{H}_{s r}^{\mathrm{ww}} \\ \mathbf{H}_{r s}^{\mathrm{ws}} & \mathbf{H}_{r r}^{\mathrm{ws}} & \mathbf{H}_{r s}^{\mathrm{ww}} & \mathbf{H}_{r r}^{\mathrm{ww}}\end{array}\right]\left[\begin{array}{c}\mathbf{u}_{s}-\left(\mathbf{u}_{\mathrm{I}}\right)_{s} \\ \mathbf{u}_{r}-\left(\mathbf{u}_{\mathrm{I}}\right)_{r} \\ \boldsymbol{\tau}_{s}-\left(\boldsymbol{\tau}_{\mathrm{I}}\right)_{s} \\ \boldsymbol{\tau}_{r}-\left(\boldsymbol{\tau}_{\mathrm{I}}\right)_{r}\end{array}\right]=\left[\begin{array}{cccc}\mathbf{G}_{s s}^{\mathrm{ss}} & \mathbf{G}_{s r}^{\mathrm{ss}} & \mathbf{G}_{s s}^{\mathrm{sw}} & \mathbf{G}_{s r}^{\mathrm{sw}} \\ \mathbf{G}_{r s}^{\mathrm{ss}} & \mathbf{G}_{r r}^{\mathrm{ss}} & \mathbf{G}_{r s}^{\mathrm{sw}} & \mathbf{G}_{r r}^{\mathrm{sw}} \\ \mathbf{G}_{s s}^{\mathrm{ws}} & \mathbf{G}_{s r}^{\mathrm{ws}} & \mathbf{G}_{s s}^{\mathrm{ww}} & \mathbf{G}_{s r}^{\mathrm{ww}} \\ \mathbf{G}_{r s}^{\mathrm{ws}} & \mathbf{G}_{r r}^{\mathrm{ws}} & \mathbf{G}_{r s}^{\mathrm{ww}} & \mathbf{G}_{r r}^{\mathrm{ww}}\end{array}\right]\left[\begin{array}{c}\mathbf{p}_{s}-\left(\mathbf{p}_{\mathrm{I}}\right)_{s} \\ \mathbf{p}_{r}-\left(\mathbf{p}_{\mathrm{I}}\right)_{r} \\ \mathbf{U}_{s}-\left(\mathbf{U}_{\mathrm{I}}\right)_{s} \\ \mathbf{U}_{r}-\left(\mathbf{U}_{\mathrm{I}}\right)_{r}\end{array}\right]$



Figure 2: Rigid model for an embedded foundation. Free surface $\Gamma_{s}\left(\mathbf{p}_{s}=0, \boldsymbol{\tau}_{s}=0\right)$ and rigid interface $\Gamma_{r}$.

On the other hand, the six degrees of freedom of the rigid body (three displacements and three rotations) can be measured from an arbitrary point of reference with coordinates $\left(x^{\text {ref }}, y^{\text {ref }}, z^{\text {ref }}\right)$ and may be organized in the rigid body displacements vector $\mathbf{u}^{\text {ref }}=\left(u^{\text {ref }}, v^{\text {ref }}, w^{\text {ref }}, \theta_{x}^{\text {ref }}, \theta_{y}^{\text {ref }}, \theta_{z}^{\text {ref }}\right)^{\mathrm{T}}$. The kinematic compatibility relations that exist between the vector of displacements of rigid body $\mathbf{u}^{\text {ref }}$ and the vector of displacements of the $i$-node $\mathbf{u}^{i}=\left(u^{i}, v^{i}, w^{i}\right)^{\mathrm{T}}$ at the interface $\Gamma_{r}$ can be written in matrix form as $\mathbf{u}^{i}=\mathbf{C}^{i} \mathbf{u}^{\text {ref }}$, where

$$
\mathbf{C}^{i}=\left[\begin{array}{cccccc}
1 & 0 & 0 & 0 & \left(z^{i}-z^{\mathrm{ref}}\right) & \left(y^{\mathrm{ref}}-y^{i}\right) \\
0 & 1 & 0 & \left(z^{\mathrm{ref}}-z^{i}\right) & 0 & \left(x^{i}-x^{\mathrm{ref}}\right) \\
0 & 0 & 1 & \left(y^{i}-y^{\mathrm{ref}}\right) & \left(x^{\mathrm{ref}}-x^{i}\right) & 0
\end{array}\right]
$$

and being $\left(x^{i}, y^{i}, z^{i}\right)$ the coordinates of the $i$-node over $\Gamma_{r}$. The kinematic compatibility relationship for all $n_{r}$ nodes in $\Gamma_{r}$ can be written as:

$$
\mathbf{u}_{r}=\mathbf{C} \mathbf{u}^{\text {ref }}
$$

being $\mathbf{u}_{r}=\left[\mathbf{u}^{1}, \ldots, \mathbf{u}^{n_{r}}\right]^{\mathrm{T}}$ and $\mathbf{C}=\left[\mathbf{C}^{1}, \ldots, \mathbf{C}^{n_{r}}\right]^{\mathrm{T}}$.

Equilibrium between the forces acting on the rigid foundation, and the tractions and fluid equivalent stresses on the soil-rigid body interface $\Gamma_{r}$ is required. Let $\mathbf{p}^{j}(x, y, z)=\left(p_{x}^{j}, p_{y}^{j}, p_{z}^{j}\right)^{\mathrm{T}}$ be the vector of tractions, $\tau^{j}(x, y, z)$ the fluid equivalent stress and $\mathbf{n}^{j}(x, y, z)=\left(n_{x}^{j}, n_{y}^{j}, n_{z}^{j}\right)^{\mathrm{T}}$ the normal vector of the $j$-element over $\Gamma_{r}$. Considering the inertial forces and the vector of resultants of the external forces acting at the center of mass of the rigid foundation $\mathbf{F}^{\mathrm{cg}}=$ $\left(F_{x}^{\mathrm{cg}}, F_{y}^{\mathrm{cg}}, F_{z}^{\mathrm{cg}}, M_{x}^{\mathrm{cg}}, F_{y}^{\mathrm{cg}}, F_{z}^{\mathrm{cg}}\right)^{\mathrm{T}}$, the equilibrium relations at the center of gravity of the rigid body can be expressed as: 


$$
\begin{aligned}
F_{k}^{\mathrm{cg}}= & \sum_{j=1}^{n_{e}} \int_{\Gamma_{r}^{j}}\left(p_{k}^{j}+\tau^{j} n_{k}^{j}\right) \mathrm{d} \Gamma_{r}^{j}-\omega^{2} M u_{k}^{\mathrm{cg}} ; k=x, y, z \\
M_{x}^{\mathrm{cg}}= & \sum_{j=1}^{n_{e}}\left(\int_{\Gamma_{r}^{j}}\left(p_{y}^{j}+\tau^{j} n_{y}^{j}\right)\left(z^{\mathrm{cg}}-z^{j}\right) \mathrm{d} \Gamma_{r}^{j}+\right. \\
& \left.\int_{\Gamma_{r}^{j}}\left(p_{z}^{j}+\tau^{j} n_{z}^{j}\right)\left(y^{j}-y^{\mathrm{cg}}\right) \mathrm{d} \Gamma_{r}^{j}\right)-\omega^{2} I_{x}^{\mathrm{cg}} \theta_{x}^{\mathrm{cg}} \\
M_{y}^{\mathrm{cg}}= & \sum_{j=1}^{n_{e}}\left(\int_{\Gamma_{r}^{j}}\left(p_{x}^{j}+\tau^{j} n_{x}^{j}\right)\left(z^{j}-z^{\mathrm{cg}}\right) \mathrm{d} \Gamma_{r}^{j}+\right. \\
& \left.\int_{\Gamma_{r}^{j}}\left(p_{z}^{j}+\tau^{j} n_{z}^{j}\right)\left(x^{\mathrm{cg}}-x^{j}\right) \mathrm{d} \Gamma_{r}^{j}\right)-\omega^{2} I_{y}^{\mathrm{cg}} \theta_{y}^{\mathrm{cg}} \\
M_{z}^{\mathrm{cg}}= & \sum_{j=1}^{n_{e}}\left(\int_{\Gamma_{r}^{j}}\left(p_{x}^{j}+\tau^{j} n_{x}^{j}\right)\left(y^{\mathrm{cg}}-y^{j}\right) \mathrm{d} \Gamma_{r}^{j}+\right. \\
& \left.\int_{\Gamma_{r}^{j}}\left(p_{y}^{j}+\tau^{j} n_{y}^{j}\right)\left(x^{j}-x^{\mathrm{cg}}\right) \mathrm{d} \Gamma_{r}^{j}\right)-\omega^{2} I_{z}^{\mathrm{cg}} \theta_{z}^{\mathrm{cg}}
\end{aligned}
$$

being $M$ the total mass, $I_{x}^{\mathrm{cg}}, I_{y}^{\mathrm{cg}}, I_{z}^{\mathrm{cg}}$ the inertia moments at the center of mass of the foundation, $\left(x^{\mathrm{cg}}, y^{\mathrm{cg}}, z^{\mathrm{cg}}\right)$ the coordinates of the section center of gravity, $n_{e}$ the number of elements in the rigid interface, $\omega$ the excitation frequency and $\left(x^{j}, y^{j}, z^{j}\right)$ the coordinates of the points over the $j$-element. In terms of the nodal values of the variables, the set of equations (9) may be expressed as:

$$
\mathbf{F}^{\mathrm{cg}}=\mathbf{E} \mathbf{p}_{r}+\mathbf{J} \boldsymbol{\tau}_{r}-\omega^{2} \mathbf{M} \mathbf{u}^{\mathrm{cg}}
$$

being $\mathbf{E}$ and $\mathbf{J}$ the matrices of equilibrium formed by integrals involving the corresponding elemental shape functions, $\mathbf{M}$ a diagonal matrix that contains the total mass and the inertia moments of the foundation, $\mathbf{p}_{r}=\left(\mathbf{p}^{1}, \ldots, \mathbf{p}^{n_{r}}\right)^{\mathrm{T}}, \boldsymbol{\tau}_{r}=\left(\tau^{1}, . ., \tau^{n_{r}}\right)^{\mathrm{T}}$ and $\mathbf{u}^{\mathrm{cg}}=\left(u^{\mathrm{cg}}, v^{\mathrm{cg}}, w^{\mathrm{cg}}, \theta_{x}^{\mathrm{cg}}, \theta_{y}^{\mathrm{cg}}, \theta_{z}^{\mathrm{cg}}\right)^{\mathrm{T}}$ the vector of displacements of the center of gravity of that foundation.

Equilibrium equations (10), defined at the center of gravity of the rigid body, can be generalized for an arbitrary point of reference considering equilibrium and kinematic relations between this point and the center of mass. These relations may be expressed in matrix form as follows:

$$
\mathbf{F}^{\mathrm{cg}}=\mathbf{T} \mathbf{F}^{\mathrm{ref}} ; \quad \mathbf{u}^{\mathrm{cg}}=\mathbf{L} \mathbf{u}^{\mathrm{ref}}
$$

being

$$
\mathbf{L}=\left[\begin{array}{cccccc}
1 & 0 & 0 & 0 & \left(z^{\mathrm{cg}}-z^{\mathrm{ref}}\right) & \left(y^{\mathrm{ref}}-y^{\mathrm{cg}}\right) \\
0 & 1 & 0 & \left(z^{\mathrm{ref}}-z^{\mathrm{cg}}\right) & 0 & \left(x^{\mathrm{cg}}-x^{\mathrm{ref}}\right) \\
0 & 0 & 1 & \left(y^{\mathrm{cg}}-y^{\mathrm{ref}}\right) & \left(x^{\mathrm{ref}}-x^{\mathrm{cg}}\right) & 0 \\
0 & 0 & 0 & 1 & 0 & 0 \\
0 & 0 & 0 & 0 & 1 & 0 \\
0 & 0 & 0 & 0 & 0 & 1
\end{array}\right]
$$

and $\mathbf{T}=\left(\mathbf{L}^{\mathrm{T}}\right)^{-1}$.

Applying boundary conditions, assuming welded contact conditions between soil and foundation rigid body, taking the kinematic relation (8) into account and writing equilibrium equations from (10) and (11) as additional equations, the systems of equation (5) results in

$$
\left[\begin{array}{cccc}
\mathbf{H}_{s s} & \mathbf{H}_{s r} \mathbf{C} & -\mathbf{G}_{s r} & \varnothing \\
\mathbf{H}_{r s} & \mathbf{H}_{r r} \mathbf{C} & -\mathbf{G}_{r r} & \varnothing \\
\varnothing & -\omega^{2} \mathbf{M} \mathbf{L} & \mathbf{E} & -\mathbf{T}
\end{array}\right]\left[\begin{array}{c}
\mathbf{u}_{s} \\
\mathbf{u}^{\mathrm{ref}} \\
\mathbf{p}_{r} \\
\mathbf{F}^{\mathrm{ref}}
\end{array}\right]=\left[\begin{array}{ccc}
\mathbf{H}_{s s} & \mathbf{H}_{s r} & -\mathbf{G}_{s r} \\
\mathbf{H}_{r s} & \mathbf{H}_{r r} & -\mathbf{G}_{r r} \\
\varnothing & \varnothing & \varnothing
\end{array}\right]\left[\begin{array}{l}
\left(\mathbf{u}_{\mathrm{I}}\right)_{s} \\
\left(\mathbf{u}_{\mathrm{I}}\right)_{r} \\
\left(\mathbf{p}_{\mathrm{I}}\right)_{r}
\end{array}\right]
$$


while (6) yields, for poroelastic soils, the following system of equations:

$$
\begin{array}{r}
{\left[\begin{array}{ccccccc}
\mathbf{H}_{s s}^{\mathrm{ss}} & -\mathbf{G}_{s s}^{\mathrm{sw}} & \mathbf{H}_{s r}^{\mathrm{ss}} \mathbf{C} & -\mathbf{G}_{s r}^{\mathrm{sw}} & -\mathbf{G}_{s r}^{\mathrm{ss}} & \mathbf{H}_{s r}^{\mathrm{sw}} & \varnothing \\
\mathbf{H}_{r s}^{\mathrm{ss}} & -\mathbf{G}_{r s}^{\mathrm{sw}} & \mathbf{H}_{r r}^{\mathrm{ss}} \mathbf{C} & -\mathbf{G}_{r r}^{\mathrm{sw}} & -\mathbf{G}_{r r}^{\mathrm{ss}} & \mathbf{H}_{r r}^{\mathrm{sw}} & \varnothing \\
\mathbf{H}_{s s}^{\mathrm{ws}} & -\mathbf{G}_{s s}^{\mathrm{ww}} & \mathbf{H}_{s r}^{\mathrm{ws}} \mathbf{C} & -\mathbf{G}_{s r}^{\mathrm{ww}} & -\mathbf{G}_{s r}^{\mathrm{ws}} & \mathbf{H}_{s r}^{\mathrm{ww}} & \varnothing \\
\mathbf{H}_{r s}^{\mathrm{ws}} & -\mathbf{G}_{r s}^{\mathrm{ww}} & \mathbf{H}_{r r}^{\mathrm{ws}} \mathbf{C} & -\mathbf{G}_{r r}^{\mathrm{ww}} & -\mathbf{G}_{r r}^{\mathrm{ws}} & \mathbf{H}_{r r}^{\mathrm{ww}} & \varnothing \\
\varnothing & \varnothing & -\omega^{2} \mathbf{M} \mathbf{L} & \varnothing & \mathbf{E} & \mathbf{J} & -\mathbf{T}
\end{array}\right]\left[\begin{array}{c}
\mathbf{u}_{s} \\
\mathbf{U}_{s} \\
\mathbf{u}^{\mathrm{ref}} \\
\mathbf{U}_{r} \\
\mathbf{p}_{r} \\
\boldsymbol{\tau}_{r} \\
\mathbf{F}^{\mathrm{ref}}
\end{array}\right]} \\
{\left[\begin{array}{ccccccc}
\mathbf{H}_{s s}^{\mathrm{ss}} & -\mathbf{G}_{s s}^{\mathrm{sw}} & \mathbf{H}_{s r}^{\mathrm{ss}} & -\mathbf{G}_{s r}^{\mathrm{sw}} & -\mathbf{G}_{s r}^{\mathrm{ss}} & \mathbf{H}_{s r}^{\mathrm{sw}} \\
\mathbf{H}_{r s}^{\mathrm{ss}} & -\mathbf{G}_{r s}^{\mathrm{sw}} & \mathbf{H}_{r r}^{\mathrm{ss}} & -\mathbf{G}_{r r}^{\mathrm{sw}} & -\mathbf{G}_{r r}^{\mathrm{ss}} & \mathbf{H}_{r r}^{\mathrm{sw}} \\
\mathbf{H}_{s s}^{\mathrm{ws}} & -\mathbf{G}_{s s}^{\mathrm{ww}} & \mathbf{H}_{s r}^{\mathrm{ws}} & -\mathbf{G}_{s r}^{\mathrm{ww}} & -\mathbf{G}_{s r}^{\mathrm{ws}} & \mathbf{H}_{s r}^{\mathrm{ww}} \\
\mathbf{H}_{r s}^{\mathrm{ws}} & -\mathbf{G}_{r s}^{\mathrm{ww}} & \mathbf{H}_{r r}^{\mathrm{ws}} & -\mathbf{G}_{r r}^{\mathrm{ww}} & -\mathbf{G}_{r r}^{\mathrm{ws}} & \mathbf{H}_{r r}^{\mathrm{ww}} \\
\varnothing & \varnothing & \varnothing & \varnothing & \varnothing & \varnothing
\end{array}\right]\left[\begin{array}{c}
\left(\mathbf{u}_{\mathrm{I}}\right)_{s} \\
\left(\mathbf{U}_{\mathrm{I}}\right)_{s} \\
\left(\mathbf{u}_{\mathrm{I}}\right)_{r} \\
\left(\mathbf{U}_{\mathrm{I}}\right)_{r} \\
\left(\mathbf{p}_{\mathrm{I}}\right)_{r} \\
\left(\boldsymbol{\tau}_{\mathrm{I}}\right)_{r}
\end{array}\right]}
\end{array}
$$

In this case, in order to define the relationship between the pore fluid and the rigid interface, an additional condition is needed at the interface between rigid body and poroelastic soil. In this work, two different contact conditions based on particular cases of the theory presented by Deresiewicz and Skalak (1963), are considered: drained and undrained contact. On one hand, if $\Gamma_{r}$ is considered as a permeable interface (drained contact), the free drainage of the pore fluid is possible, then the fluid equivalent stress $\boldsymbol{\tau}_{r}=0$ and the normal fluid displacement $\mathbf{U}_{r}$ is unknown. On the other hand, if the rigid interface is impermeable (undrained contact), the fluid does not soak through $\Gamma_{r}$, then the fluid equivalent stress $\boldsymbol{\tau}_{r}$ is unknown and the normal fluid displacement $\mathbf{U}_{r}$ is completely constrained by the rigid surface and equal to the normal displacement of the solid skeleton $\mathbf{n}_{r} \mathbf{u}_{r}$, where $\mathbf{n}_{r}$ is the normal vector of the $\Gamma_{r}$ rigid interface. Taking (8) into account, this last condition can be expressed in (14) as $\mathbf{U}_{r}=\mathbf{n}_{r} \mathbf{C} \mathbf{u}^{\text {ref }}$.

In both cases, displacements $\mathbf{u}^{\text {ref }}$ and reactions $\mathbf{F}^{\text {ref }}$ at the point of reference are unknowns of the system and will be used to couple, through kinematic compatibility and equilibrium, the foundation to the base of the superstructure, discretized as presented in the next section.

\section{Building modelling. Two-noded Timoshenko beam finite ele- ments}

In this work, buildings are discretized using three-dimensional two-noded Timoshenko beam finite elements for frequency-domain problems, that take axial and torsional degrees of freedom into account, and that can be seen as an enhancement of the element proposed by Friedman and Kosmatka (1993). Let $u, v, w, \theta_{x}, \theta_{y}$ and $\theta_{z}$ be the six degrees of freedom (three displacements and three rotations) defined at each node, as shown in figure 3. The vectors of nodal forces $\mathbf{F}_{i}$ and $\mathbf{F}_{j}$ are coherent with the vectors of nodal displacements $\mathbf{u}_{i}$ and $\mathbf{u}_{j}$.

For buildings with non-symmetrical cross-section, the shear-center (center of stiffness) $\mathrm{C}$ and center of gravity $\mathrm{G}$ of the cross-section might not be located at the same point (see figure 4). The differences between the coordinates of $\mathrm{C}$ and $\mathrm{G}$ represent the eccentricities along $x$-direction $\left(e_{x}\right)$ and $y$-direction $\left(e_{y}\right)$. In these cases, the dynamic analysis forces to write the stiffness matrix given by these authors at $\mathrm{G}$ for every $i j$-element of the building model. This fact makes possible that the dynamic equilibrium equations of the $i j$-element may be expressed at the center of gravity of the section as follows

$$
\left[\begin{array}{l}
\mathbf{F}_{i} \\
\mathbf{F}_{j}
\end{array}\right]^{\mathrm{G}}=\left(\mathbf{K}_{i j}^{\mathrm{G}}-\omega^{2} \mathbf{M}_{i j}^{\mathrm{G}}\right)\left[\begin{array}{c}
\mathbf{u}_{i} \\
\mathbf{u}_{j}
\end{array}\right]^{\mathrm{G}}
$$




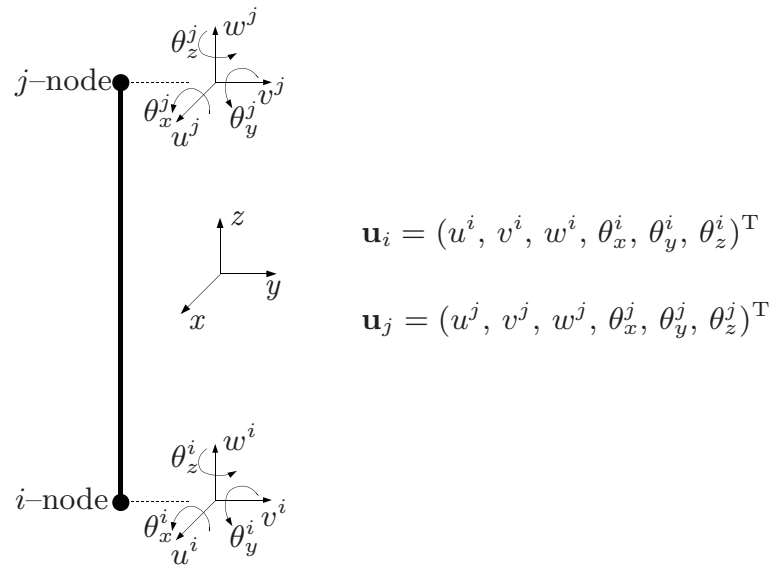

Figure 3: Two-noded Timoshenko beam finite element used for building discretization.
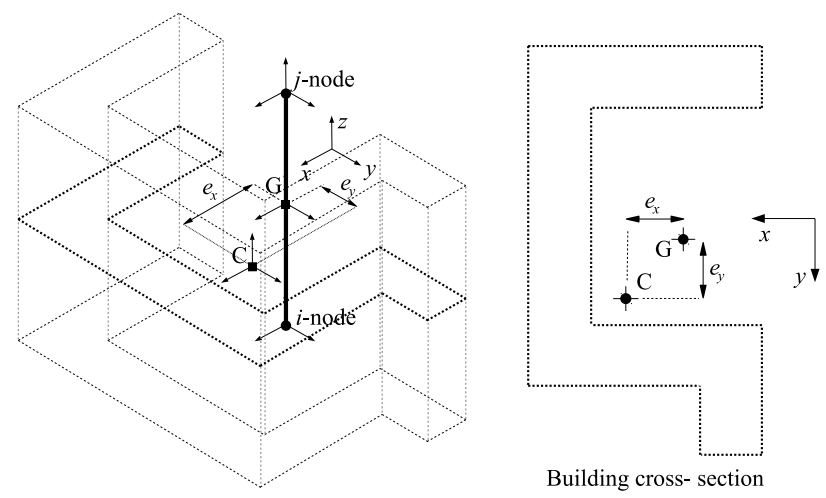

Figure 4: Building model with generic non-symmetrical cross-section.

where $\mathbf{K}_{i j}^{\mathrm{G}}$ is the stiffness matrix defined at the center of gravity, and $\mathbf{M}_{i j}^{\mathrm{G}}$ is the consistent mass-matrix of the $i j$-element, obtained as the addition of two matrices, the first one associated to the translational inertia and the second one associated to the rotatory inertia (see Friedman and Kosmatka, 1993).

In order to build $\mathbf{K}_{i j}^{\mathrm{G}}$, a simple procedure is implemented. The starting point is the element stiffness matrix proposed by Friedman and Kosmatka (1993) adapted so as to represent a threedimensional problem and to include the torsional term $\mu J / L$ (where $\mu$ is the material shear modulus, $J$ is the torsional constant, and $L$ is the element length). Such element stiffness matrix is defined at the shear center of the section and is written at the center of gravity (where inertial forces are applied) through the following kinematic and equilibrium relations between $\mathrm{C}$ and $\mathrm{G}$ for the $i j$-element,

$$
\left[\begin{array}{l}
\mathbf{u}_{i} \\
\mathbf{u}_{j}
\end{array}\right]^{\mathrm{C}}=\left[\begin{array}{ll}
\mathbf{S} & 0 \\
0 & \mathbf{S}
\end{array}\right]\left[\begin{array}{l}
\mathbf{u}_{i} \\
\mathbf{u}_{j}
\end{array}\right]^{\mathrm{G}} ; \quad\left[\begin{array}{l}
\mathbf{F}_{i} \\
\mathbf{F}_{j}
\end{array}\right]^{\mathrm{G}}=\left[\begin{array}{cc}
\mathbf{S}^{\mathrm{T}} & 0 \\
0 & \mathbf{S}^{\mathrm{T}}
\end{array}\right]\left[\begin{array}{l}
\mathbf{F}_{i} \\
\mathbf{F}_{j}
\end{array}\right]^{\mathrm{C}}
$$

where

$$
\mathbf{S}=\left[\begin{array}{cccccc}
1 & 0 & 0 & 0 & 0 & -e_{y} \\
0 & 1 & 0 & 0 & 0 & e_{x} \\
0 & 0 & 1 & 0 & 0 & 0 \\
0 & 0 & 0 & 1 & 0 & 0 \\
0 & 0 & 0 & 0 & 1 & 0 \\
0 & 0 & 0 & 0 & 0 & 1
\end{array}\right]
$$

Thus, the stiffness matrix of an eccentric beam element can be obtained from: 


$$
\mathbf{K}_{i j}^{\mathrm{G}}=\left[\begin{array}{cc}
\mathbf{S}^{\mathrm{T}} & 0 \\
0 & \mathbf{S}^{\mathrm{T}}
\end{array}\right] \mathbf{K}_{i j}^{\mathrm{C}}\left[\begin{array}{cc}
\mathbf{S} & 0 \\
0 & \mathbf{S}
\end{array}\right]
$$

Eccentricities $e_{x}$ and $e_{y}$, shear correction factors $\alpha_{x}$ and $\alpha_{y}$, and torsional constant $J$ corresponding to building cross-sections were obtained using the module 'Sections' in the BeamTool of ANSYS ${ }^{\circledR}$.

\section{Results}

This section presents, for validation and illustration purposes, results corresponding to three different problems: a) a soil-structure interaction problem where the soil is modelled as a viscoelastic region, b) the study of the influence of considering a soil of poroelastic nature in the previous SSI problem, and c) the study of a SSSI problem, i.e., of the influence of nearby structures in the response of the system.
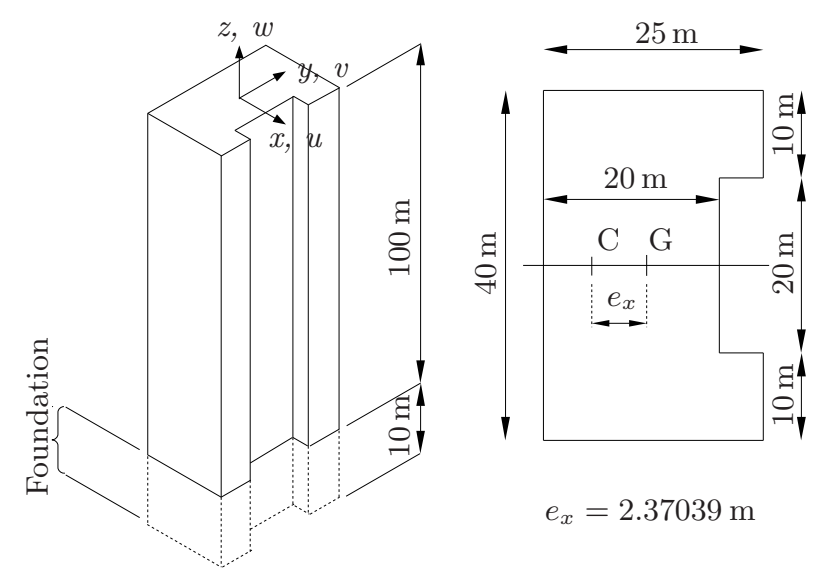

Figure 5: Building model dimensions.

Figure 5 shows the dimensions and the U-shaped cross-section of the 100 meters high building involved in all cases of study. The fundamental fixed-base frequency of the building is $f_{\mathrm{fb}}^{x z}=$ $0.564 \mathrm{~Hz}\left(\mathrm{~T}_{\mathrm{fb}}^{x z} \approx 1.773 \mathrm{~s}\right)$ in the $x z-$ plane and $f_{\mathrm{fb}}^{y z}=0.920 \mathrm{~Hz}\left(\mathrm{~T}_{\mathrm{fb}}^{y z} \approx 1.087 \mathrm{~s}\right)$ in the $y z$-plane. The rest of properties used in order to model the superstructure as a Timoshenko beam are: equivalent shear modulus $\mu_{\mathrm{b}}=3.0 \cdot 10^{8} \mathrm{~N} / \mathrm{m}^{2}$, equivalent linear density $\rho_{\mathrm{b}}=2.7 \cdot 10^{5} \mathrm{~kg} / \mathrm{m}$, Poisson's ratio $\nu_{\mathrm{b}}=0.2$ and hysteretic damping ratio $\xi_{\mathrm{b}}=0.05$.

Table 1 presents the properties of the cross-section of the building, being $I_{x}, I_{y}$ the inertia moments, $J$ the torsional constant, $A$ the area and $\alpha_{x}, \alpha_{y}$ the shear correction factors.

Table 1: Properties of the building cross-section for the FE definition

\begin{tabular}{cccccccc}
\hline$I_{x}\left(\mathrm{~N} \cdot \mathrm{m}^{2}\right)$ & $I_{y}\left(\mathrm{~N} \cdot \mathrm{m}^{2}\right)$ & $J\left(\mathrm{~N} \cdot \mathrm{m}^{4}\right)$ & $A\left(m^{2}\right)$ & $e_{x}(\mathrm{~m})$ & $e_{y}(\mathrm{~m})$ & $\alpha_{x}$ & $\alpha_{y}$ \\
\hline 130000.0 & 40763.9 & 84281.6 & 900.0 & 2.37039 & 0.0 & 0.886399 & 0.748341 \\
\hline
\end{tabular}

\subsection{Soil-structure interaction problem in viscoelastic soil}

This section presents results corresponding to a SSI problem involving a building founded on an equivalent elastic soil with the properties of the drained poroelastic medium (elastic drained soil) as in Todorovska and Al Rjoub (2006a). The properties of such equivalent drained elastic soil are: 
shear wave velocity $c_{\mathrm{s}}=300 \mathrm{~m} / \mathrm{s}$, Poisson's ratio $\nu_{\mathrm{s}}=0.3$, damping hysteretic ratio $\xi_{\mathrm{s}}=0.05$ and density $\rho_{\mathrm{s}}=1620 \mathrm{~kg} / \mathrm{m}^{3}$.

For validation purposes, results will be compared against those of the more rigorous multidomain BEM presented in Maeso et al (2002, 2004, 2005); Aznárez et al (2006). When using such approach to solve the problem, all domains defining the geometry (soil, foundation and building) are modelled as linear homogeneous isotropic viscoelastic regions. Figure 6(a) shows the mesh of boundary elements used for this purpose. The code is able to take the symmetry properties of the problem into account, so only one half of the total geometry needs to be meshed. The element size must be smaller than the half-wave length at the corresponding region for the highest frequency of analysis, in this case $10 \mathrm{~Hz}$. Free-surface extension and number of elements, are defined by performing convergence analyses of the variables of interest for different meshes. The properties of the foundation are coincident with the parameters previously defined for the building domain, except for the value of the shear modulus, which is assumed to be one hundred times stiffer than the equivalent shear modulus of the Timoshenko beam used to model the building. On the other hand, the mesh used to solve the problem with the BEM-FEM model is presented in figure 6(b). Free-surface and foundation-soil interfaces coincide with those of the mesh used for the multidomain BEM approach (figure 6(a)). The buried part of the building is modelled now as a perfectly rigid domain using the formulation explained in section 3 so, in this case, only the perfectly rigid interfaces and the free surface of the soil need to be meshed with boundary elements. The building itself is now discretized using two-noded Timoshenko finite elements (10 finite elements with 10 meters length) instead of boundary elements. The reference point of the rigid body is located at the top of the foundation domain, exactly on the symmetry $x$-axis and at the center of gravity $\mathrm{G}$ of the cross-section (see detail in figure 6(b)).

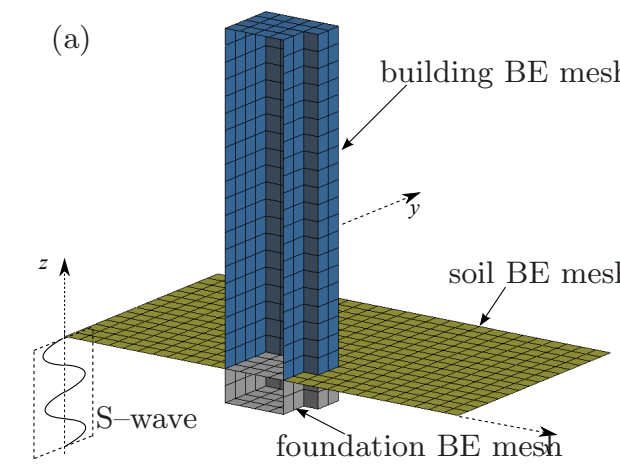

Coupled BEM model

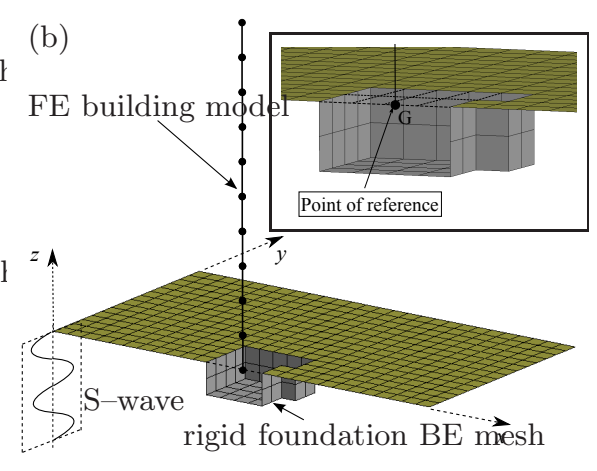

BEM-FEM model

Figure 6: (a) Multidomain BEM mesh. (b) BEM-FEM mesh, and detail of the coupling at the point of reference.

Figure 7 shows the modulus of the vertical displacement $w$ at the top and the base of the building considering $\mathrm{P}$-wave as excitation, and being $w_{\mathrm{ff}}$ the vertical free field displacement. On the other hand, when the system is subjeted to $\mathrm{S}$-waves inducing displacements along $y$-direction, the variables of interest are the transversal displacements $v$ and the bending rotation $\theta_{x}$ around $x-$ axis, together with the torsional rotation $\theta_{z}$ due to the eccentricity $e_{x}$ of the cross-section. Figure 8 shows the frequency response functions relating these three variables measured at the base and the top of the building, to the transversal free field displacement $v_{\mathrm{ff}}$ and the half width of the section $(\mathrm{a}=20 \mathrm{~m})$.

Figures 7 and 8 show good agreement between the multidomain BEM and the BEM-FEM models. Both models are able to capture the effects of soil-structure interaction, evident from the comparison against the fixed-base response (represented with a black dashed line where appropiate), as resonant frequencies and peak responses decrease significantly. The largest differences appear when comparing torsional responses at the top. Discrepancies come from two sources: a) nonuniform torsion, which is not taken into account by the finite element, and b) results for bending and torsional rotation from the multidomain BEM are computed indirectly from the displacements 

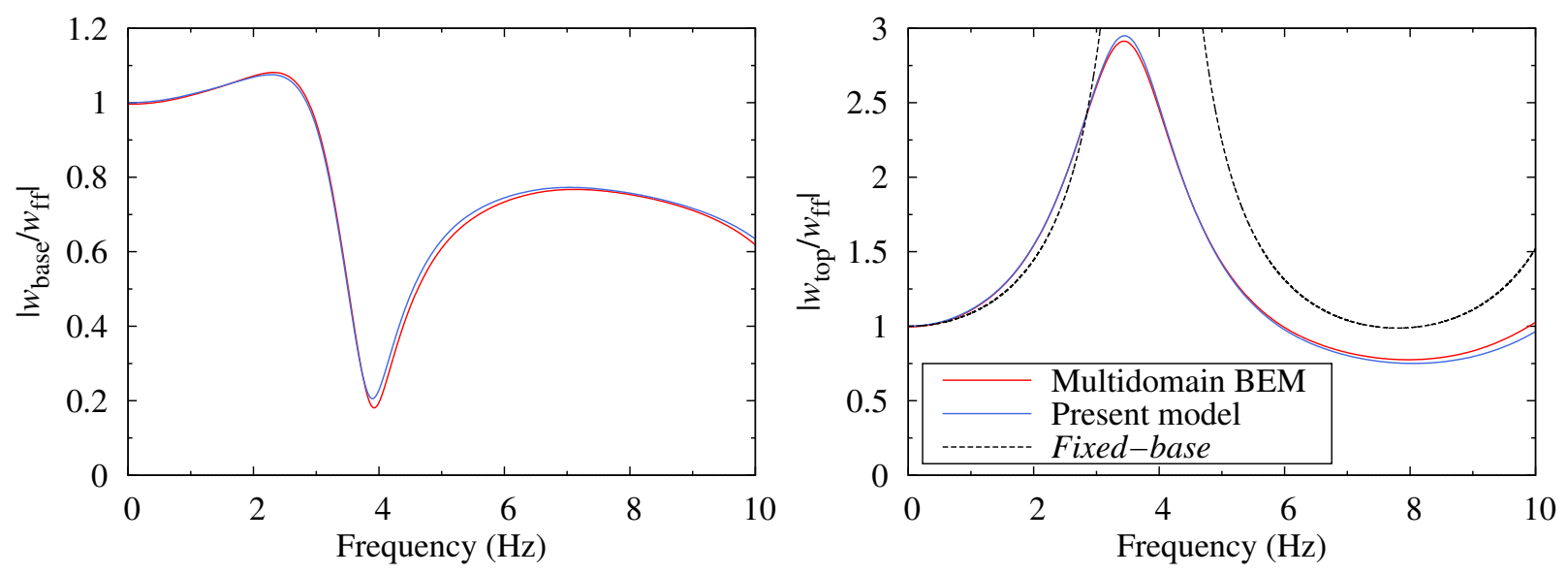

Figure 7: Comparison between BEM and BEM-FEM models. Frequency response functions at the base and the top of the building for vertical displacements $w$ normalized with the free field displacement $w_{\text {ff }}$ due to vertically-incident $\mathrm{P}$-waves.

of the mesh nodes. The results presented in the next subsections are obtained using only the BEM-FEM model.

\subsection{Soil-structure interaction problem in poroelastic soils}

In order to study the influence over the previous SSI problem of considering a soil of poroelastic nature, this section presents results regarding the dynamic response of the building when founded on elastic or poroelastic soils. The properties of such poroelastic medium (after Todorovska and Al Rjoub, 2006a) are: soil porosity $\phi=0.4$, Poisson's ratio $\nu=0.3$, density of the solid phase $\rho_{\mathrm{s}}=$ $2700 \mathrm{~kg} / \mathrm{m}^{3}$, shear modulus of the solid phase $\mu_{\mathrm{s}}$ (corresponding to a dry shear wave velocity $\left.c_{\mathrm{s}, \mathrm{dry}}=\sqrt{\mu_{\mathrm{s}} /\left((1-\phi) \rho_{\mathrm{s}}\right)}=300 \mathrm{~m} / \mathrm{s}\right)$, density of the fluid phase $\rho_{\mathrm{f}}=1000 \mathrm{~kg} / \mathrm{m}^{3}$, compressibility of the fluid phase $K_{\mathrm{f}}=2.2 \times 10^{9} \mathrm{~N} / \mathrm{m}^{2}$, and apparent added density $\rho_{\mathrm{a}}=300 \mathrm{~kg} / \mathrm{m}^{3}$. The Biot's constant are $Q=(1-\phi) K_{\mathrm{f}}=8.80 \cdot 10^{8} \mathrm{~N} / \mathrm{m}^{2}$ and $R=\phi K_{\mathrm{f}}=1.32 \cdot 10^{9} \mathrm{~N} / \mathrm{m}^{2}$. Five different cases of soils will be considered. For the elastic type, two different models are studied: elastic drained soil (properties of soil in section 5.1) and elastic undrained soil (saturated soil). In this last case, the soil properties are: the shear modulus $\mu_{\mathrm{us}}=1.458 \cdot 10^{8} \mathrm{~N} / \mathrm{m}^{2}$, the density $\rho_{\mathrm{us}}=2020 \mathrm{~kg} / \mathrm{m}^{3}$, the damping hysteretic ratio $\xi=0.05$ and the value of the Poisson ratio $\nu_{\text {us }}=0.4876$, which is related to Biot's parameters as follows:

$$
\nu_{\mathrm{us}}=\frac{\lambda_{\mathrm{s}}+\mu_{\mathrm{s}}+\frac{(Q+R)^{2}}{R}}{2\left[\lambda_{\mathrm{s}}+\mu_{\mathrm{s}}+\frac{(Q+R)^{2}}{R}\right]}
$$

where $\lambda_{\mathrm{s}}$ is the Lame's constant. In the poroelastic case, three different models are studied characterized by dissipation constants $b=0,1.569 \cdot 10^{5}$ and $1.569 \cdot 10^{6} \mathrm{~N} \cdot \mathrm{s} / \mathrm{m}^{4}$, corresponding to Darcy's hydraulic conductivities $k=\infty, 10^{-2}$ and $10^{-3} \mathrm{~m} / \mathrm{s}$, according to the relationship (see e.g. Bougacha and Tassoulas, 1991):

$$
b=\rho_{\mathrm{f}} g \frac{\phi^{2}}{k}
$$

where $g\left(\mathrm{~m} / \mathrm{s}^{2}\right)$ is the gravity acceleration. Undrained contact condition between rigid foundation and soil are always assumed, except when $b=0$, case in which both drained and undrained contact conditions are studied. The results presented in figures 9 and 10 were obtained considering undrained contact condition. The mesh used in this study is shown in figure 6(b).

Figure 9 presents the frequency response functions $\left|w / w_{\mathrm{ff}}\right|,\left|u / w_{\mathrm{ff}}\right|$ and $\mathrm{a} \cdot\left|\theta_{y} / w_{\mathrm{ff}}\right|$ representing vertical and horizontal displacements and bending rotation at the base and the top of the building. 

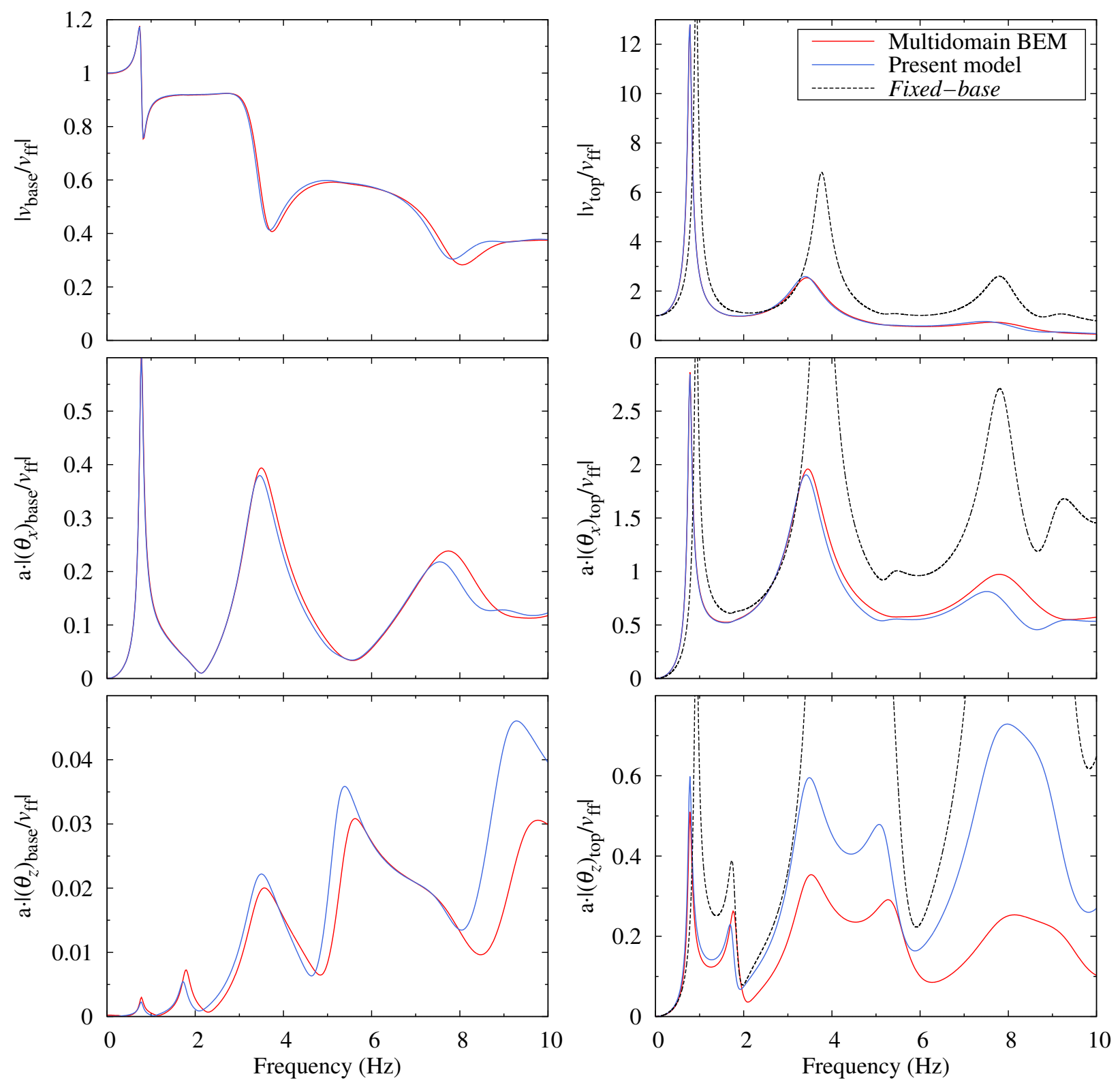

Figure 8: Comparison between BEM and BEM-FEM models. Frequency response functions at the base and the top of the building for transversal displacements $v$ in $y$-direction, bending rotations $\theta_{x}$ around $x$-axis and torsional rotations $\theta_{z}$, normalized by the free field displacement $v_{\mathrm{ff}}$ due to vertically-incident $\mathrm{S}$-waves.

Fixed-base response at the top of the building is also included for reference (black dashed line). The building is subjected to vertically-incident $\mathrm{P}$-waves, but the presence of the non-symmetrical structural section generates not only vertical displacements $w$ but also horizontal displacements in the $x$-direction $u$ and bending rotations $\theta_{y}$. The model captures not only the soil-structure interaction, but also the influence of the type of soil in the response of the structure, which produces significant differences for frequencies above $4 \mathrm{~Hz}$. Differences in the response at the top of the building can be seen, particularly at the peaks. The small box in the plot of the frequency response function of the displacement $w$ at the top shows a detailed view of the first peak. It can be seen that that the first mode frequency slightly increases, and also the response functions, for the water-saturated soils.

Figure 10 presents the response at the top and bottom of the building when subjected to vertically-incident $\mathrm{S}$-waves producing transversal displacements along the $y$-direction. Due to the torsional eccentricity of the building, torsional rotation $\mathrm{a} \cdot\left|\theta_{z} / v_{\mathrm{ff}}\right|$ exists together with transversal 


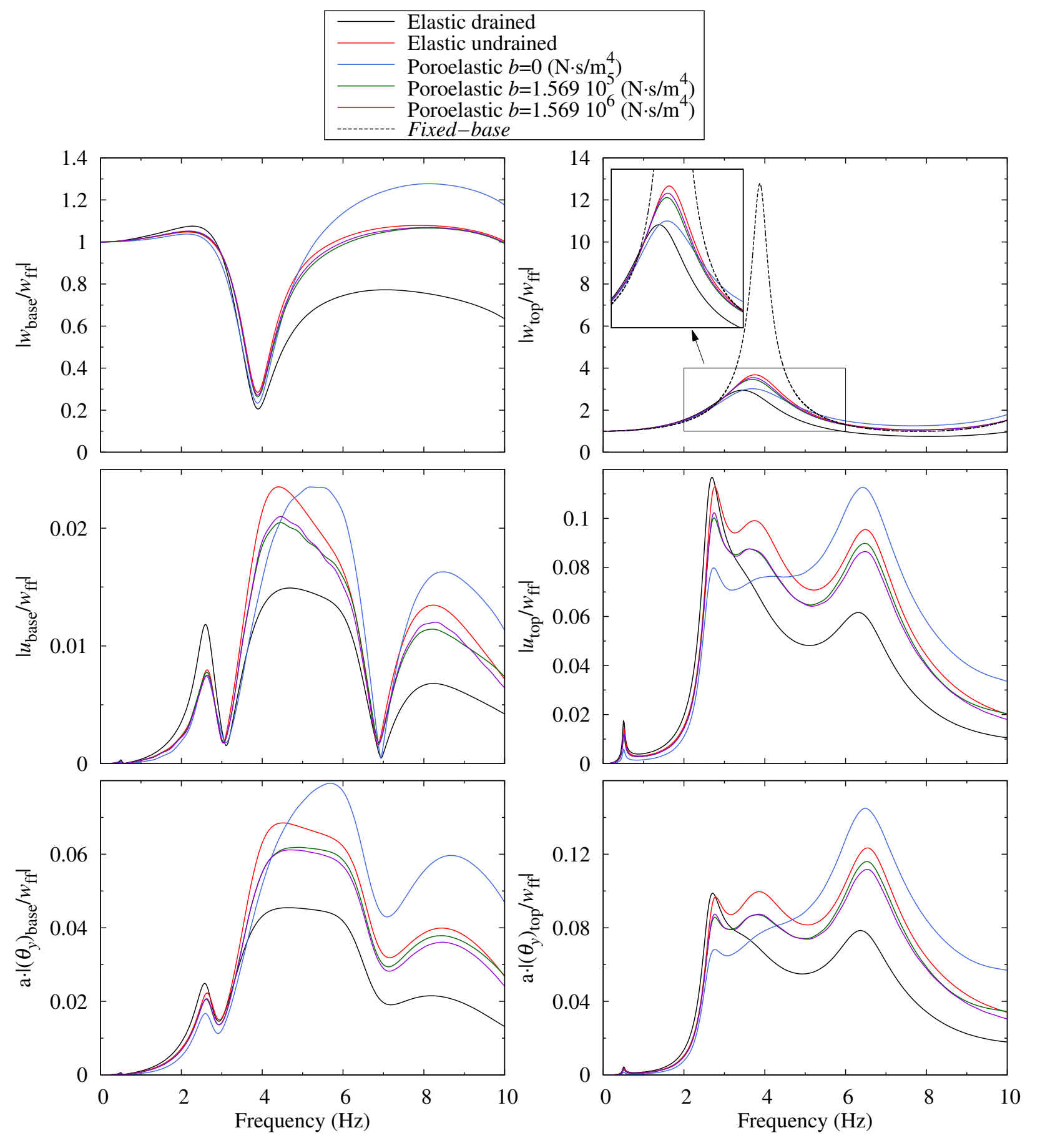

Figure 9: Vertical displacements $\left|w / w_{\mathrm{ff}}\right|$, horizontal displacements $\left|u / w_{\mathrm{ff}}\right|$ and bending rotations $\mathrm{a} \cdot\left|\theta_{y} / w_{\mathrm{ff}}\right|$ at the base and the top of the building due to vertically-incident $\mathrm{P}$-waves. Elastic model (drained and undrained) and poroelastic model with different values of the dissipation constant 'b'.

displacement $\left|v / v_{\mathrm{ff}}\right|$ and bending rotation $\mathrm{a} \cdot\left|\theta_{x} / v_{\mathrm{ff}}\right|$. In this case, the influence of the soil model on the response is very small. Only a slight increase in the fundamental frequency and a reduction of the peak are observed in for the water-saturated soils. As expected, if the soil is considered as elastic undrained, the response of the structure is similar to that computed for poroelastic soils with high values of 'b' in both problems.

The model can be used not only to study the effects of the value of the dissipation constant ' $b$ ' of the soil in the response, but also the effects of the contact condition between the rigid foundation and the soil. All results presented above assumed undrained contact condition. Now, drained and 



Figure 10: Transversal displacement $\left|v / v_{\mathrm{ff}}\right|$, bending rotations $\mathrm{a} \cdot\left|\theta_{x} / v_{\mathrm{ff}}\right|$ and torsional rotations $\mathrm{a} \cdot\left|\theta_{z} / v_{\mathrm{ff}}\right|$ at the base and the top of the building due to vertically-incident $\mathrm{S}$-waves. Elastic model (drained and undrained) and poroelastic model with different values of the dissipation constant 'b'.

undrained contact conditions will be compared for $b=0$. For this purpose, figure 11 shows the frequency response functions of the vertical displacement $\left|w / w_{\mathrm{ff}}\right|$, horizontal displacement $\left|u / w_{\mathrm{ff}}\right|$ and bending rotation $\mathrm{a} \cdot\left|\theta_{y} / w_{\mathrm{ff}}\right|$ at the base and the top of the building for vertically-incident $\mathrm{P}$-waves; and figure 12 presents transversal displacement $\left|v / v_{\mathrm{ff}}\right|$, bending rotation $\mathrm{a} \cdot\left|\theta_{x} / v_{\mathrm{ff}}\right|$ and torsional rotation $\mathrm{a} \cdot\left|\theta_{z} / v_{\mathrm{fff}}\right|$ at the base and the top of the building when the excitation is a $\mathrm{S}$-wave.

The results show a significant influence of the contact condition when the system is subjected to $\mathrm{P}$-waves, but a negligible influence for $\mathrm{S}$-waves. Similar effects of the contact condition can be found in Japón et al (1997) when studying dynamic stiffness functions of foundations. 


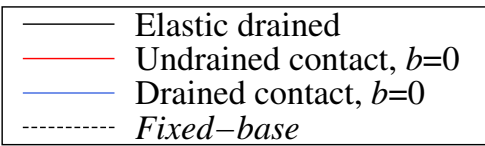
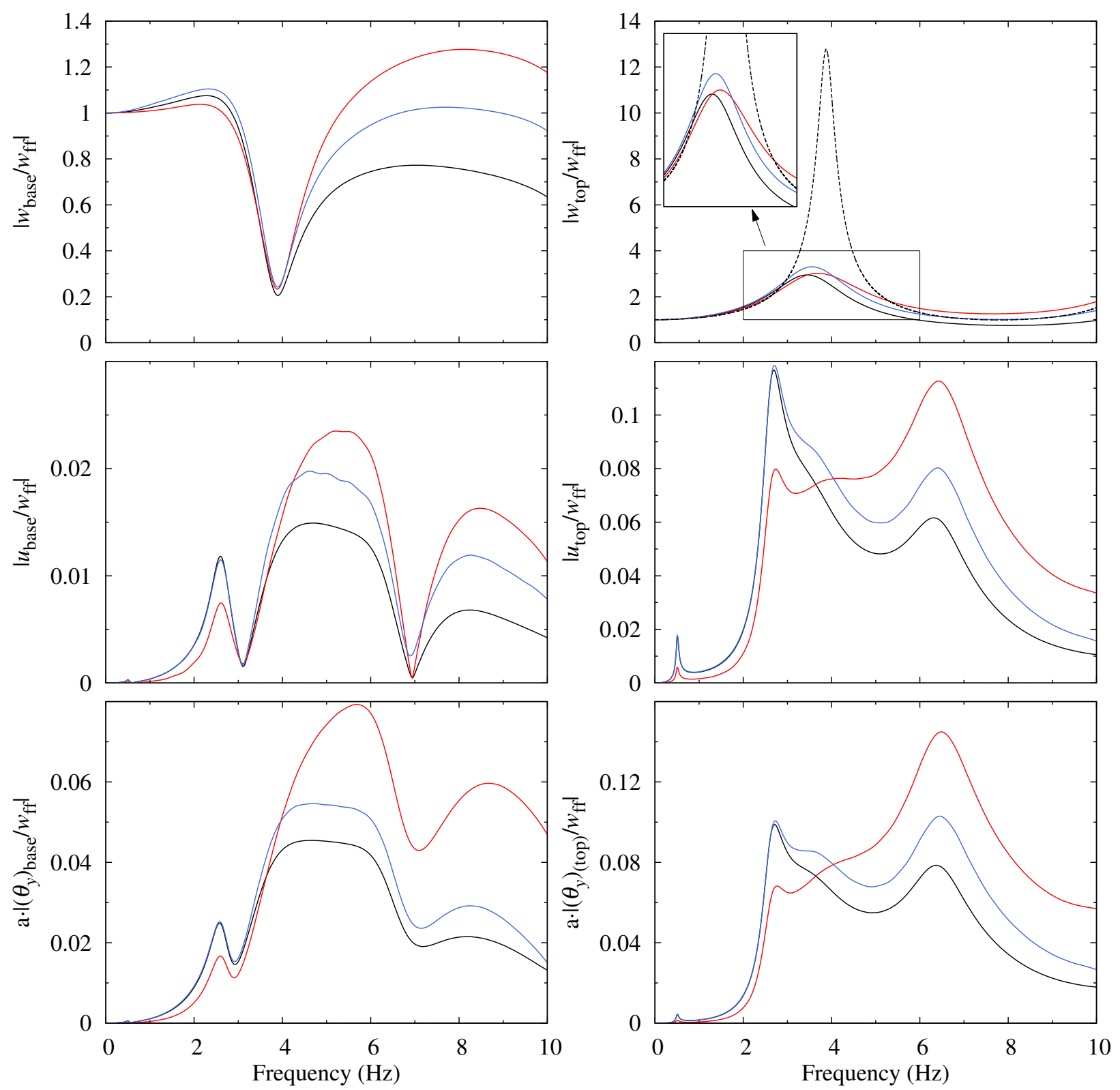

Figure 11: Vertical displacements $\left|w / w_{\mathrm{ff}}\right|$, horizontal displacements $\left|u / w_{\mathrm{ff}}\right|$ and bending rotations $\mathrm{a} \cdot\left|\theta_{y} / w_{\mathrm{ff}}\right|$ at the base and the top of the building due to vertically-incident $\mathrm{P}$-waves, for different hydraulic contact conditions.

\subsection{Structure-soil-structure interaction}

The use of the BEM-FEM model presented above to study the effects of structure-soil-structure interaction are explored in this section by presenting results of the dynamic response of the system when two identical buildings are founded close to each other. The soil is considered as the elastic drained domain described in section 5.1. Figure 13(a) shows a sketch of the problem in which the geometrical and mechanical properties of buildings and soil correspond to those described in the introductory part of the section 5. The two identical buildings are placed symmetrically with respect to each other, being 'd' the closest distance between them. Figure 13(b) shows the BEM- 

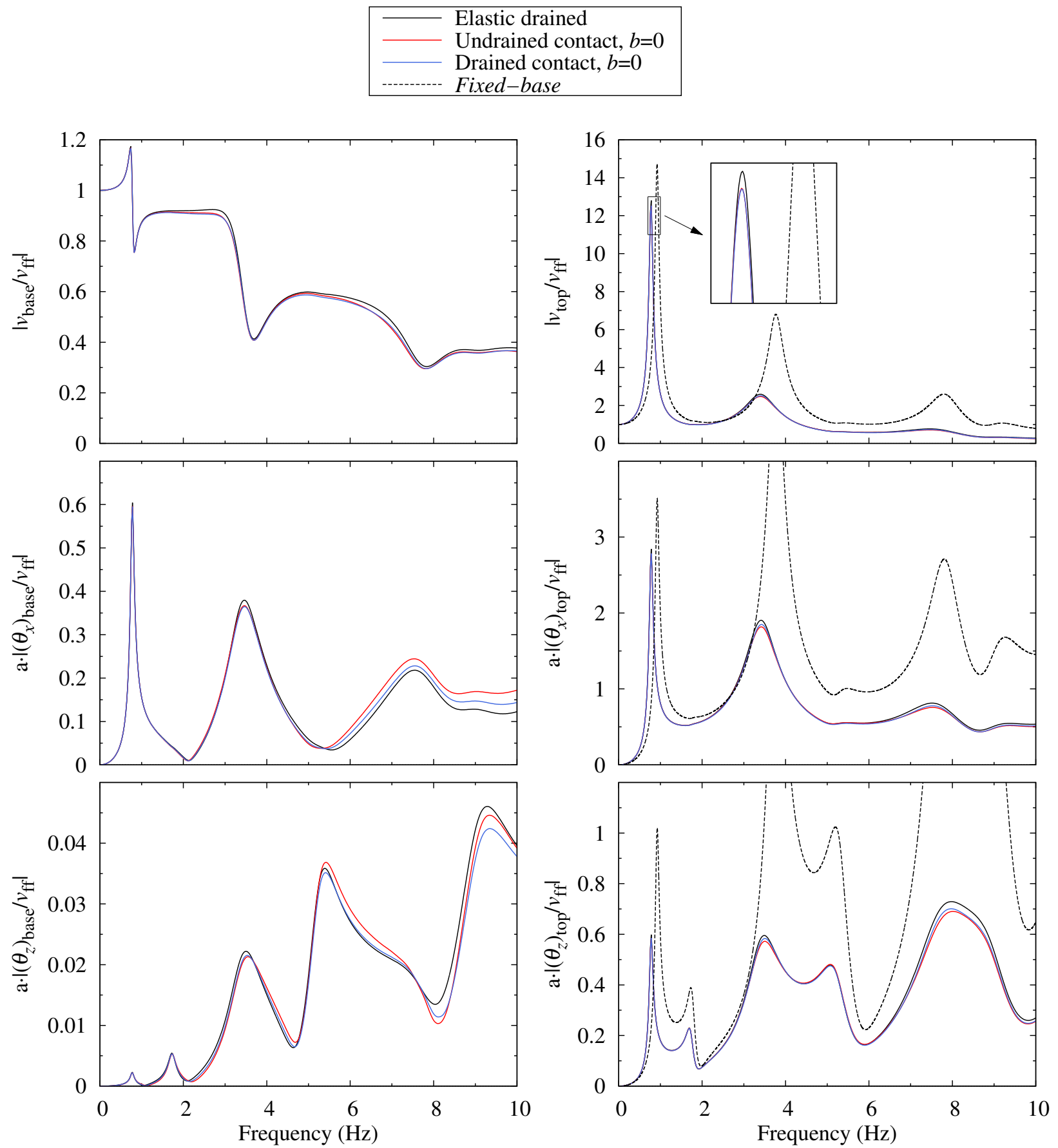

Figure 12: Transversal displacements $\left|v / v_{\mathrm{ff}}\right|$, bending rotations $\mathrm{a} \cdot\left|\theta_{x} / v_{\mathrm{ff}}\right|$ and the torsional rotations $\mathrm{a} \cdot\left|\theta_{z} / v_{\mathrm{fff}}\right|$ at the base and the top of the building due to vertically-incident $\mathrm{S}$-waves, for different hydraulic contact conditions.

FEM mesh used in the study. The response have been computed for two different values of the distance 'd' (25 and 50 meters) and considering a Rayleigh wave propagating from $-x$ as the incident field. The amplitude of this Rayleigh incident wave is assumed to be constant along the whole free surface of the soil (zero damping in the incident field).

Figure 14 presents the dynamic response of the system in terms of horizontal displacement $u$, vertical displacement $w$ and rotation $\theta_{y}$ at the base and the top of both buildings, normalized with the horizontal displacement of the incident wave $u_{\mathrm{ff}}$. The response considering only the presence of one building is included in both figures for reference. Structure-soil-structure interaction is 


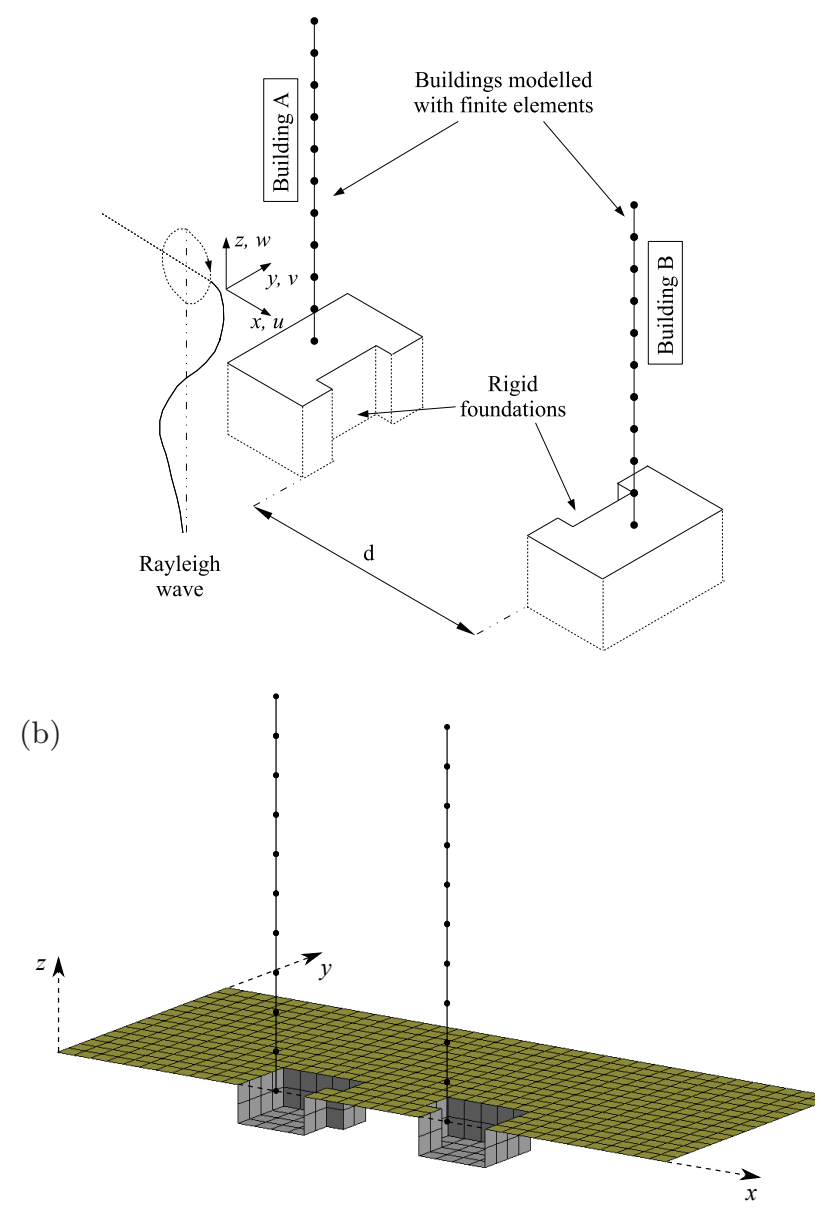

Figure 13: (a) Isometric view sketch of the problem of two buildings modelled with the BEM-FEM model. (b) BEM-FEM mesh of two buildings (only one half of the geometry is meshed).

more significant on the vertical response, where the first building (building A) to be reached by the wavefront develops larger peak responses than the second building (building B), whose response is smaller than that of the single building in the whole frequency range.

\section{Conclusions}

A Boundary Element - Finite Element formulation has been proposed in this work for the timeharmonic study of soil-structure and structure-soil-structure interaction problems involving buildings on foundations that can be assumed to be much stiffer than the surrounding soil. This symplifying assumption allows to reduce the number of degrees of freedom of the problem by modelling the foundation as a rigid body. Further reduction in the computational cost of the analysis is obtained by modelling the superstructure as a Timoshenko beam.

For this purpose, a previous multidomain BEM formulation has been enhanced in order to include coupling with rigid regions. Viscoelastic and poroelastic domains can be considered. The introduction of Timoshenko beams in the model, coupled to those rigid bodies, has also been implemented. The finite elements used to discretize such Timoshenko beams are presented in such a way that the eccentricity of the structural section and its torsional response can be taken into account.

Results corresponding to the seismic response of buildings and groups of buildings under $\mathrm{S}, \mathrm{P}$ or 

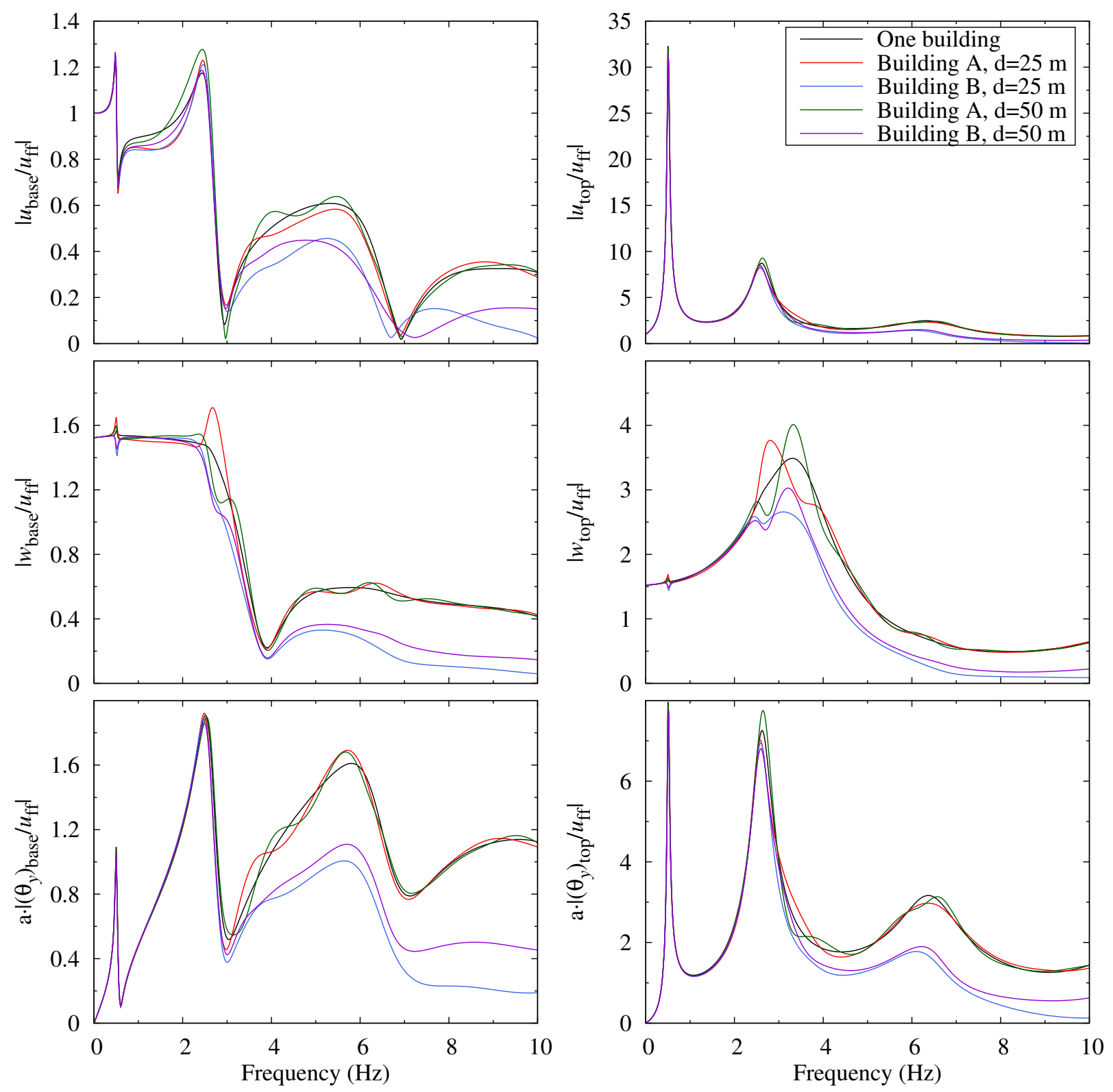

Figure 14: Transversal displacements $\left|u / u_{\mathrm{ff}}\right|$, vertical displacements $\left|w / u_{\mathrm{ff}}\right|$ and bending rotations $\mathrm{a} \cdot\left|\theta_{y} / u_{\mathrm{ff}}\right|$ at the base and the top of the buildings due to incident Rayleigh waves.

Rayleigh waves are presented for validation purposes first, and in order to illustrate the capabilities of the model afterwards. The influence of the poroelastic natures of the soil is shown to be, in the case of study, not significant when the system is subjected to shear waves, but important for compressional waves. On the other hand, and from a single study comprising a system of two nearby identical structures subjected to Rayleigh waves, structure-soil-structure interaction is shown to affect the response of the buildings in such a way that the response of a single one is different from that of the group.

\section{Acknowledgments}

This work was supported by the Subdirección General de Proyectos de Investigación of the Ministerio de Economía y Competitividad (MINECO) of Spain and FEDER through research project BIA2010-21399-C02-01 and also by the Agencia Canaria de Investigación, Innovación y Sociedad de la Información (ACIISI) of the Government of the Canary Islands and FEDER through research 
project ProID20100224. A. Santana is recipient of the FPI research fellowship BES-2009-029161 from the MINECO. The authors are grateful for this support.

\section{References}

Aliabadi MH (2002) The Boundary Element Method. Vol 2. Applications in Solids and Structures. John Wiley \& Sons.

Aznárez JJ (2002) Efectos de los fenómenos de interacción incluyendo factores espaciales y sedimentos de fondo en la respuesta sísmica de presas bóveda. PhD thesis, Universidad de Las Palmas de Gran Canaria.

Aznárez JJ, Maeso O, Domínguez J (2006) BE analysis of bottom sediments in dynamic fluidstructure interaction problems. Engineering Analysis with Boundary Elements 30(2):124-136

Biot MA (1956) Theory of propagation of elastic waves in a fluid-saturated porous solid. I: Low frequency range. Journal of the Acoustical Society of America 28(2):168-178

Bougacha S, Tassoulas JL (1991) Seismic response of gravity dams II: Effects of sediments. Journal of Engineering Mechanics (ASCE) 117(8):1839-1850

Deresiewicz H, Skalak R (1963) On uniqueness in dynamic poroelasticity. Bulletin of the Seismological Society of America 53(4):783-788

Domínguez J (1992) Boundary element approach for dynamic poroelastic problems. International Journal for Numerical Methods in Engineering 35(2):307-324

Domínguez J (1993) Boundary Elements in Dynamics. Computational Mechanics Publication: Southampton and Elsevier Applied Science: New York

Friedman Z, Kosmatka J (1993) An improved two-node timoshenko beam finite element. Computers \& Structures 47(3):473-481

Hejal R, Chopra AK (1989) Earthquake analysis of a class of torsionally-coupled buildings. Earthquake Engineering \& Structural Dynamics 18(3):305-323

Japón B, Gallego R, Domínguez J (1997) Dynamic stiffness of foundations on saturated poroelastic soils. Journal of Engineering Mechanics 123(11):1121-1129

Luco JE (1986) Soil-structure interaction effects on the seismic response of tall chimneys. Soil Dynamics and Earthquake Engineering 5(3):170-177

Luco JE, Cortesse L (1973) Dynamic structure-soil-structure interaction. Bulletin of the Seismological Society of America 63(4):1289-1303

Luco JE, Wong HL (1982) Response of structures to non-vertically incident seismic waves. Bulletin of the Seismological Society of America 72(1):275-302

Maeso O, Aznárez JJ, Domínguez J (2002) Effects of space distribution of excitation on seismic response of arch dams. Journal of Engineering Mechanics (ASCE) 128(7):759-768

Maeso O, Aznárez JJ, Domínguez J (2004) Three-dimensional models of reservoir sediment and effects on the seismic response of arch dams. Earthquake Engineering \& Structural Dynamics 33(10):1103-1123

Maeso O, Aznárez JJ, García F (2005) Dynamic impedances of piles and groups of piles in saturated soils. Computers \& Structures 83(10-11):769-782, boundary Element Methods 
Simpson IC (1978) On the interaction of rayleigh surface waves with structures. Earthquake Engineering \& Structural Dynamics 6(3):247-263

Thomazo LH, Mesquita E (2007) On strategies to incorporate rigid body conditions in an indirect version of the boundary element method. In: Proc of Congresso de Métodos Numéricos em Engenharia (CMNE)/Congresso Ibero Latino-Americano sobre Métodos Computacionais em Engenharia, (CILAMCE), 06/2007, Porto, Portugal, vol 1, pp 1-21

Todorovska MI, Al Rjoub Y (2006a) Effects of rainfall on soil-structure system frequency: Examples based on poroelasticity and a comparison with full-scale measurements. Soil Dynamics and Earthquake Engineering 26(6-7):708-717

Todorovska MI, Al Rjoub Y (2006b) Plain strain soil-structure interaction model for a building supported by a circular foundation embedded in a poroelastic half-space. Soil Dynamics and Earthquake Engineering 26(6-7):694-707

Todorovska MI, Trifunac MD (1990) Analytical model for building-foundation-soil interaction: incident P-, SV- and Rayleigh waves. Report No. CE 90-91, Dept. of Civil Engrg, University of Southern California, Los Angeles, California

Vega J, Aznárez JJ, Santana A, Alarcón E, Padrón LA, Pérez JJ, Maeso O (2013) On soil-structure interaction in large non-slender partially buried structures. Bulletin of Earthquake Engineering 11(5):1403-1421

Wang S, Schmid G (1992) Dynamic structure-soil-structure interaction by FEM and BEM. Computational Mechanics 9(5):347-357

Wong HL, Trifunac MD (1975) Two-dimensional, antiplane, building-soil-building interaction for two or more buildings and for incident planet SH waves. Bulletin of the Seismological Society of America 65(6):1863-1885 